\title{
Nick in Time
}

\section{Matthew Lee ${ }^{1}$}

Published online: 16 January 2020

(C) Springer Science+Business Media, LLC, part of Springer Nature 2020

Episodes stitched together by whiskey, Winehouse, what ifs, enough soot \& tar for a bubble bath.

Do forty-four pack years doom me like Doctor Faust's twenty-four with Mephistopheles? Screw the math.

The sun scoffs at the small spark cupped in my hands.

A loose cotton thread frayed by mindless fingering, quivering, I pray to be cut before I learn how much carcinoma costs, what lingering means. I see myself as ash in a pink salt urn

The stars despise me for stomping out my light.

before my fibrosis tastes like burnt tin foil. If I run everyday, eat more salad than fries, if I stop starting mornings with a drag \& lies, could I pause/rewind this spinning mortal coil?

But the moon has felt the pain of rebirth and longing.

It's in her dry eyes, her cracked lips and yellowed teeth, a smile that knows the illusion of reprieve.

Matthew Lee

mattdleemd@gmail.com

1 The Warren Alpert Medical School, Brown University, Box G-9999, Providence, RI 02912, USA 